\title{
The Management of Human Capital Based on Dynamic Model
}

$$
\text { Yuetong Shen }{ }^{1, a} \text {, Hao Yan }{ }^{1, b} \text {, Nuo Chen }{ }^{1, c} \text { and Xiangling } \mathrm{Fu}^{1, \mathrm{~d}}
$$

${ }^{1}$ School of Software Engineering, Beijing University of Posts and Telecommunications, Beijing, 100876, China

\author{
asyt950219@163.com, b25015965.com, "853427957@qq.com, \\ dfuxiangling@bupt.edu.cn
}

Keywords: human capital, dynamic model, the rate of churn.

\begin{abstract}
In this paper, we build a model to simulate the dynamic procedure of personnel changing and the human capital management of employees. This paper builds a personnel network model to illustrate the relationship among the employees. The human capital model calculates the value of human capital in a mathematic method, and the uncertainty measurement model generates the value of loyalty with the index matrix. The models link to each other and make up the personnel-changing model, whose variables' changes represent the dynamic process. As case studies, this paper sticks to the rate of churn and the personnel changing in the organization. In different cases, this paper simulates the dynamic procedure,and the conclusion demonstrates that the model is able to map the human capital in the organization.
\end{abstract}

\section{Background}

The importance of human capital management (HCM) as a competitive tool and the relationship between human resource management and organizational performance has been the subject of systematic research (e.g. see Truss, 2001; Huselid, 1995; Delery and Doty, 1996; Becker and Gerhart, 1996)[1-3].

The competitive advantages of an organization largely depend on human capital. Human capital management focuses on people and the adjustment of their relationship, and the actions with leading affections. "Churn" of the organization, which means the resulting turbulence when people leaving for other jobs or retiring are replaced. Therefore a fluid network of human capital within an organization is vital to understand the personnel loyalties to the company and map the human capital in the organization.

\section{Introduction}

There are three modes of personnel changes: external recruiting, internal promoting and leaving because of natural or unnatural reasons. For the HR apartment, they need to cut down the unnatural leaving and control the internal promoting. Keeping the balance is their most important mission. Therefore, this paper combines the scientific methods with the reality and builds a personnel-changing model based on loyalty, related degree, human capital and external factors.

Human Capital. Human capital is the stock of knowledge, habits, social and personality attributes, including creativity, embodied in the ability to perform labor so as to produce economic value.

Loyalty. In an organization, the loyalty of employees can influence the motivation in working and the probability of churn. Measures should be taken if the loyalty decreases. It's a fluid process to measure the loyalty.

\section{Assumptions}

1) Some other economic factors are not considered in the paper, such as stock equity and bonus.

2) The employees are all at a suitable age period for working. 


\section{Model}

The content of the paper is aiming at building a dynamic human capital \& personnel-changing network model to show the fluid changes within the employees and the influence thereof. The model includes the employee elements and the functions of measuring attributes.

Personnel Network Model. In order to represent the fluid process of personnel, the paper builds a personnel network model, based on the complex network model.

The network model represents employees and their relations with nodes and edges; each node has 10 attributes with relevant values. The model contains $n$ nodes and $n$ ! edges.

Employee Node. The internal structure of the personnel nodes is illustrated in Fig. 1 The structure of the personnel node

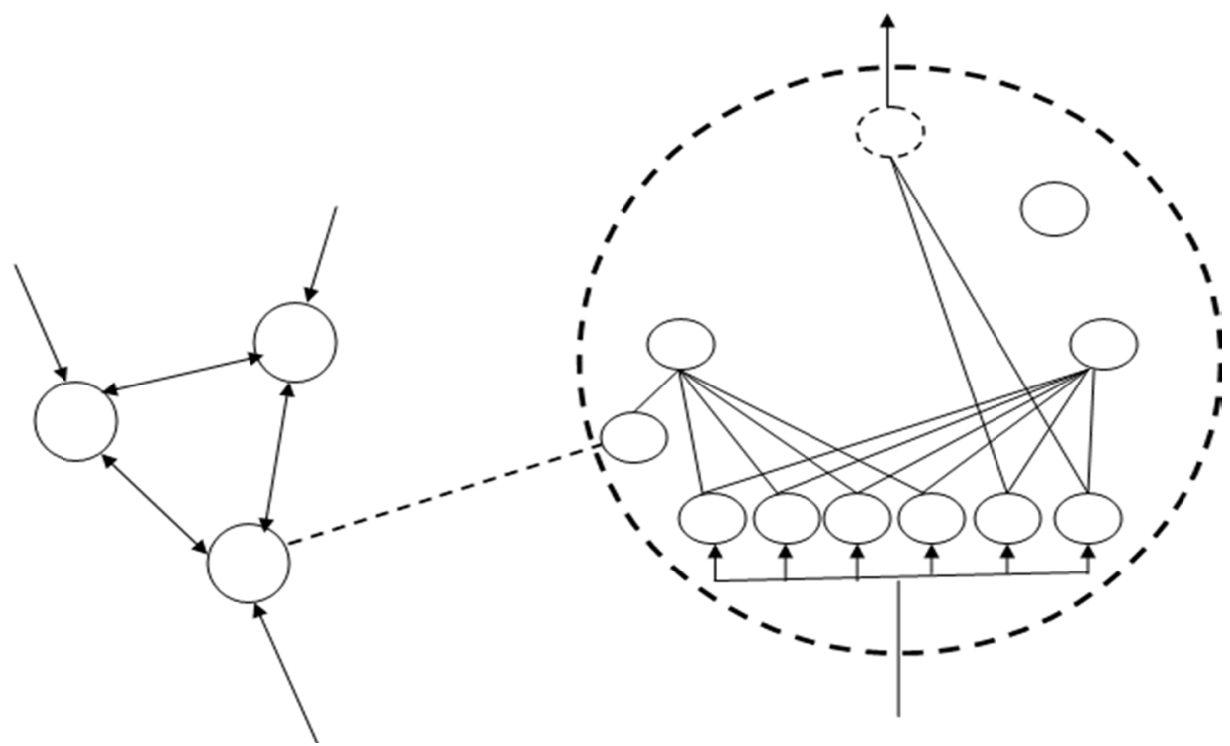

Fig. 1 The structure of the personnel node

Each employee node contains 10 attributes, listed in

Table 1 The attributes of the employee nodes.

Table 1 The attributes of the employee nodes

\begin{tabular}{|c|c|c|}
\hline Attributes & Function & Comments \\
\hline Number & $\begin{array}{c}\text { Unique number to } \\
\text { distinguish the employee }\end{array}$ & Sequentially increase from 1 \\
\hline Apartment & $\begin{array}{l}\text { The apartment the employee } \\
\text { belongs to }\end{array}$ & Represent by 1 apart_n \\
\hline Position & $\begin{array}{l}\text { The position of the } \\
\text { employee }\end{array}$ & Represent by $1 \sim$ pos_n \\
\hline Working years & $\begin{array}{c}\text { The working years of the } \\
\text { employee }\end{array}$ & \\
\hline Loyalty & & $\begin{array}{l}\text { Calculated by the model } \\
\text { following }\end{array}$ \\
\hline Human capital & & $\begin{array}{l}\text { Calculated by the model } \\
\text { following }\end{array}$ \\
\hline Salary & & Calculated by year \\
\hline Training cost & & Calculated by year \\
\hline Rehiring cost & $\begin{array}{c}\text { The cost of hiring if the } \\
\text { employee leaves }\end{array}$ & \\
\hline Rehiring time & $\begin{array}{c}\text { The time needed if the } \\
\text { employee leaves }\end{array}$ & \\
\hline
\end{tabular}

In the model, the node will be clear if the employee leaves. 
Employee Link. In the personnel network model, the link between the employee nodes represents the related degree between the two nodes, which is the standard to measure the effect to the other peer employee when one changed.

The relation degree is calculated from the apartment, position and the relationship. The apartment connection contains: same apartment, affiliation apartment, apartment in the same level, and unrelated apartment. The position connection contains: the same position, affiliation position, and the vital position (such as CEO). Obviously, the link of each two employees is bidirectional.

\section{Human Capital Model}

In the model, human capital is regarded as the standard of the employees' qualities, which is a vital factor that affects the personnel changes.

$$
P_{b}=\frac{Y_{b}+O \cdot H_{b}}{1+R_{b}}-K
$$

$H_{b}$ is the contribution rate of the employee, $R_{b}$ is risk coefficient, $K$ is the cost on the employee, which contains: the cost of training, the cost of hiring, and the cost of leaving. It can be calculated directly with the linear apportionment method.

The risk coefficient above is described as the risk of hiring and the risk of leaving. The former one is related to the position, and the latter one is related to the loyalty. The human capital model is also a fluid model, thus changing with the personnel network model.

\section{Uncertainty Measurement Model.}

In order to measure the loyalty of the specific positions in a mathematical method, this paper build an uncertainty measurement model.

Suppose that $\mathrm{x}_{1}, \mathrm{x}_{2}, \ldots, \mathrm{x}_{\mathrm{n}}$ respectively represents one of the objects to be evaluated, and let $X=\left\{x_{1}, x_{2}, \ldots, x_{n}\right\}$. And there are $\mathrm{m}$ indexes to evaluate $x_{i}\left(x_{i} \in X\right)$. They are represented by $I=\left\{i_{1}, i_{2}, \ldots, i_{m}\right\}$. The $\mathrm{x}_{i j}$ means the observed value of $x_{i}$, at the viewpoint of $i_{j}$. Let $C=$ $\left\{c_{1}, c_{2}, \cdots, c_{k}\right\}$ be the evaluation space, $c_{k}(1 \leq k \leq K)$ is the $k$ th level of evaluation. In the following model we take the index $i_{j}$ as an example.

The uncertainty measurement of a single index. We assign $\mu_{i j k}=\mu\left(x_{i j} \in c_{k}\right)$ to stand for the degree that the evaluation of $x_{i}$ belongs to level $k$. As required, there are:

$$
\left\{\begin{array}{l}
0 \leq \mu_{i j k} \leq 1 \\
\mu\left(x_{i j} \in \bigcup_{k=1}^{k} C_{k}\right)=\sum_{k=1}^{k} \mu\left(x_{i j} \in C_{k}\right) \\
\mu\left(x_{i j} \in C\right)=1 \\
(i=1,2, ? \cdot \cdot, h ; j=1,2, \cdots, m ; k=1,2, \cdots, K)
\end{array}\right.
$$

Then $\mu_{i j k}$ is the uncertainty measurement, or measurement, for short.

$$
\left(\mu_{i j k}\right)_{m \times k}=\left|\begin{array}{cccc}
\mu_{i 11} & \mu_{i 12} & \ldots & \mu_{i 1 k} \\
\mu_{i 21} & \mu_{i 22} & \ldots & \mu_{i 2 k} \\
\ldots & \ldots & \ldots & \ldots \\
\mu_{i m 1} & \mu_{i m 2} & \ldots & \mu_{i m k}
\end{array}\right| \quad i=(1,2, \ldots, n)
$$

The weight of the index. The measurement vector, which lets the evaluation of $x_{i}$ belongs to $c_{1}, c_{2}, \cdots, c_{k}$ level, is:

$$
\mu_{i j}=\left(\mu_{i j 1}, \mu_{i j 2}, \ldots, \mu_{i j k}\right)
$$

Suppose that the information entropy decided by $\mu$ is:

$$
H(j)=-\sum_{k=1}^{k} \mu_{i j k} \cdot \log \mu_{i j k}
$$

Let 


$$
\left\{\begin{array}{l}
V_{i j}=1-\frac{H(j)}{\log K}=1+\frac{1}{\log K} \sum_{k=1}^{k} \mu_{i j k} \cdot \log \mu_{i j k} \\
W_{i j}=\frac{V_{i j}}{\sum_{i=1}^{m} V_{i j}} \\
0 \leq W_{i j} \leq 1 \\
\sum_{i=1}^{m} W_{i j}=1
\end{array}\right.
$$

$W_{i j}$ is the classification weight of $x_{i}$ on index $i_{j}$,

The comprehensive evaluation

$$
W_{i}=\left\{w_{i 1}, w_{i 2}, \cdots, w_{i m}\right\}
$$

$\mu_{i}$ is the evaluation vector of $x_{i}$.

$$
\begin{aligned}
& \mu_{i}=W_{i} \cdot\left(\mu_{i j k}\right)_{m \times k}=\left(w_{i 1}, w_{i 2}, \cdots, w_{i m}\right)\left|\begin{array}{cccc}
\mu_{i 11} & \mu_{i 12} & \ldots & \mu_{i 1 k} \\
\mu_{i 21} & \mu_{i 22} & \ldots & \mu_{i 2 k} \\
\ldots & \ldots & \ldots & \ldots \\
\mu_{i m 1} & \mu_{i m 2} & \ldots & \mu_{i m k}
\end{array}\right| \\
& =\left(\mu_{i 1}, \mu_{i 2}, \cdots, \mu_{i m}\right)
\end{aligned}
$$

\section{Verification}

Model initialization. To verify the model, this paper simulates the initial position loyalty in the organization. The paper first verifies that our model can draw to a meaningful and understandable conclusion. The paper uses the Random Number Functions to generate the value of positions' attributes as in Fig. 2 and transforms the values into the valid form needed in the model.
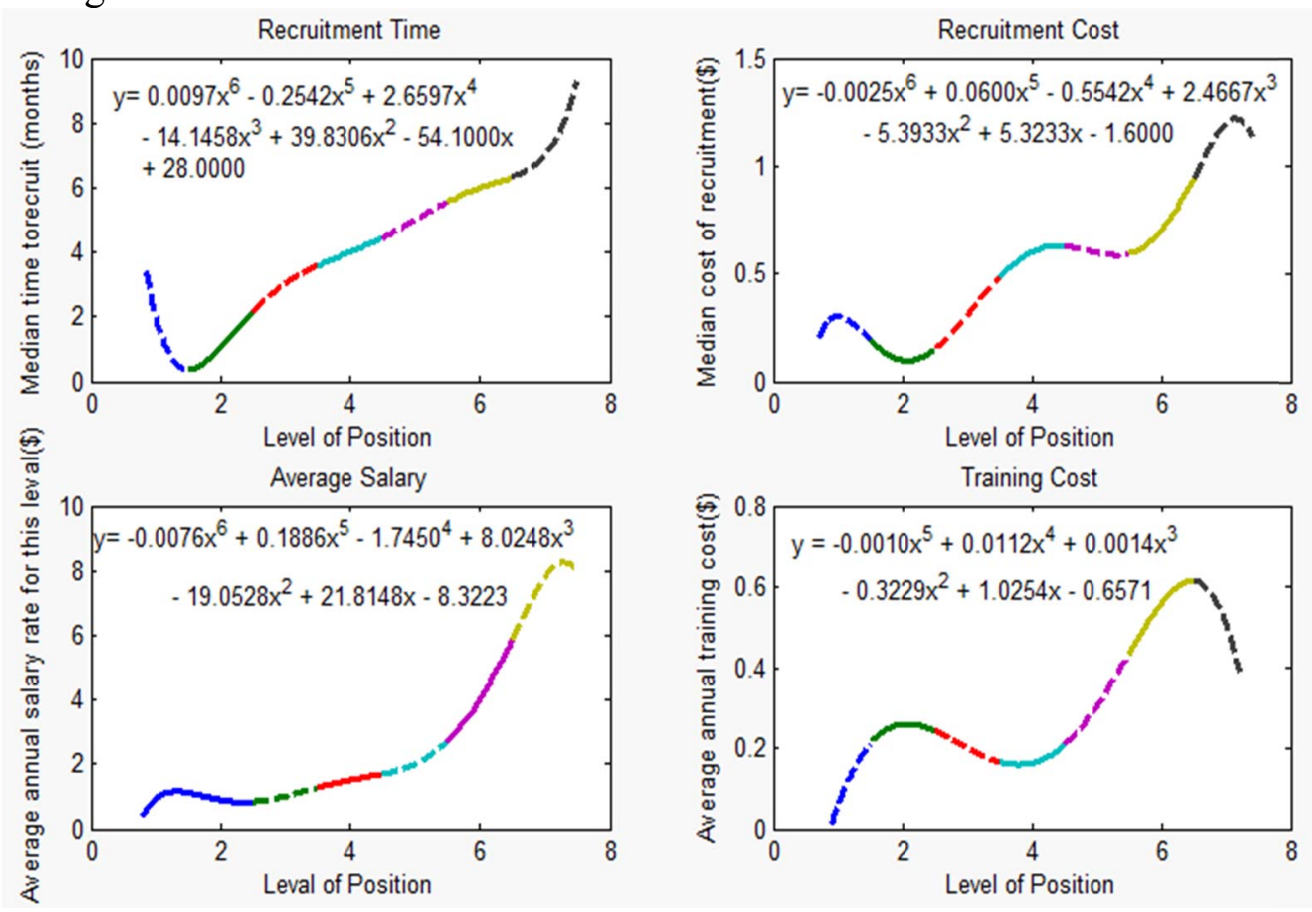

Fig. 2

We divide each part of graph by the regular ratio of employees in certain position levels, thus getting the value of $T_{b}, C_{b}$, and $Y_{b}$ and $N_{b}$ of each employees in the human capital model. 


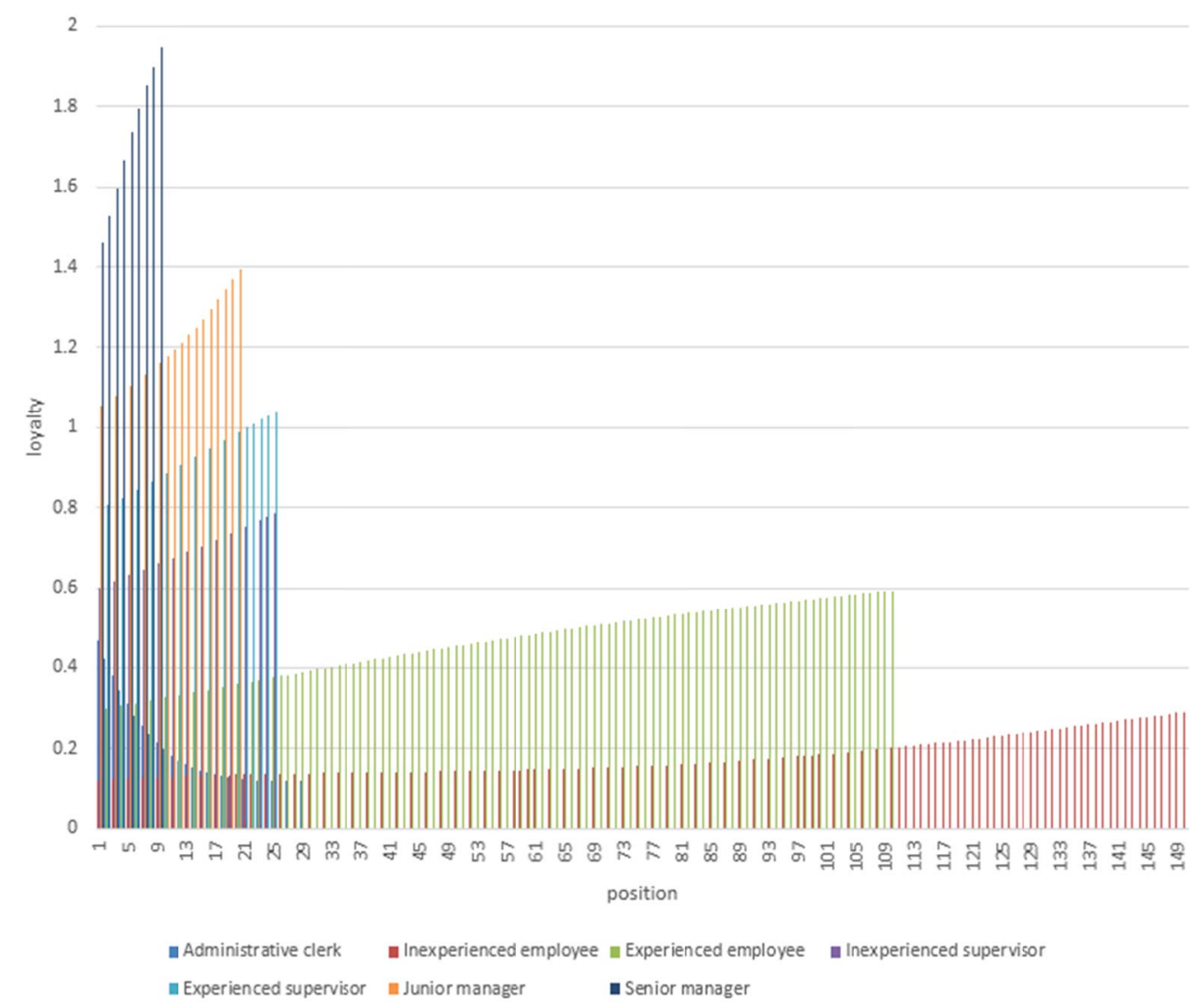

Fig. 3 loyality comparison in the whole organization

In order to find out the loyalty level of the positions in the organization in the early stages, we build to show more clearly, the figure omit the CEO, whose loyalty (about 2.4) is much higher than others. From the figure, we can see that the densest part is between loyalty $0 \sim 0.5$. Hence, we find out the scope, which can represent the initial lowest level of loyalty in the whole organization. In another word, the people below the level, which is about 0.133 , are the most disloyal ones. It's necessary to have a motivated workforce on these employees to control the risk of churn.

\section{Dynamic model}

Initially, the paper simulates the process with the change of attributes and values. What should be noticed is that the necessary positions shouldn't be vacant. Then, the two models calculate the loyalty and the human capital. At last, the model will give the value of the link. The fluid process is generated to help analyze. The leaving of employees is related to the loyalty. Especially the middle managers that often feel stuck in their jobs. These mid-level positions are critical ones that suffer high turn-over. If a necessary position is vacant, the HR apartment needs to decide which employee is qualified to fill the vacancy by human capitals.

\section{References}

[1] Eleni T. Stavrou, Christakis Charalambous, SteliosSpiliotis. Human resource management and performance: A neural network analysis, European Journal of Operational Research, 2007, pp. 453-467.

[2] Ya gan, O. \& Gligor, V. (2012) Analysis of complex contagions in random multiplex networks. Phys. Rev. E, 86, 036103.

[3] Michael C.Pasqual, Olivier L. de Weck. Multilayer network model for analysis and management of change propagation. International Conference on Engineering Design, ICED’05, Denmark, August 2011, pp.15-18.

[4] MikkoKivelä, Alexandre Arenas, Marc Barthelemy, James P. Gleeson, Yamir Moreno, Mason A. 
Porter. (2013). Multilayer Networks, J. Complex Networks, 2(3): 203-271 (2014); arXiv preprint arXiv:1309.7233, 2013.

[5] Mucha, P. J., Richardson, T., Macon, K., Porter, M. A. \& Onnela, J.-P. (2010) Community structure in time-dependent, multiscale, and multiplex networks. Science, 328, 876-878.

[6] Jo, H.-H., Baek, S. K. \& Moon, H.-T. (2006) Immunization dynamics on a two-layer network model. Physica A, 361, 534-542.

[7] Sun, Y. \& Han, J. (2013) Mining heterogeneous information networks: a structural analysis approach. ACM SIGKDD Explor. Newslett., 14, 20-28.

[8] Martin, C. D. \& Porter, M. A. (2012) The extraordinary SVD. Am. Math. Monthly, 119, 838851.

[9] M.A.H.Farquad.Vadlamani Ravi,S.Bapi Raju. Churn prediction using comprehensible support vector machine: An analytical CRM application, (2008).

[10]Gorman, J. C., Cooke, N. J., \& Winner, J. L. (2006). Measuring team situation awareness in decentralized command and control environments. Ergonomics, 49, 1312-1325.

[11]Cooke, N. J., Gorman, J. C., \& Winner, J. L. (2007). Team cognition. In F. Durso, R. Nickerson, S. Dumais, S. Lewandowsky, \& T. Perfect (Eds.), Handbook of applied cognition (2nd ed., pp. 239-268). New York: Wiley. 